\title{
Genome Sequence Resource of Fusarium brachygibbosum Padwick Strain HN-1, a Causal Agent of Maize Stalk Rot Disease
}

\author{
Hafiz Abdul Haseeb, ${ }^{1,2}$ Sajjad Hyder, ${ }^{3}$ Meixu Gao, ${ }^{1}$ and Wei Guo ${ }^{1, \dagger}$ \\ ${ }^{1}$ Institute of Food Science and Technology, Chinese Academy of Agricultural Sciences/Key Laboratory \\ of Agro-products Quality and Safety Control in Storage and Transport Process, Ministry of Agriculture \\ and Rural Affairs, Beijing 100193, P. R. China \\ ${ }^{2}$ Directorate General of Pest Warning and Quality Control of Pesticides, Punjab, Lahore, Pakistan \\ ${ }^{3}$ Department of Botany, Government College Women University, Sialkot, Pakistan
}

\begin{abstract}
Fusarium brachygibbosum Padwick, the causal agent of stalk rot disease, is a threat to the maize crop in China. However, genomic information of the pathogen is not available yet. The current study presented the genomic information of $F$. brachygibbosum, isolated from maize. The genome size is $40.36 \mathrm{Mb}$ and consists of 12,510 genes. The GC content is $47.95 \%$, and there are 913 predicted secretory proteins. The presented genomic data highlighted the virulence features, plant-microbe interaction ability, genes associated with the pathogen's metabolic processes, and host-binding ability. Presented results would extend our knowledge of the pathogen and help us develop suitable disease management strategies.
\end{abstract}

Fusarium spp. are notorious worldwide pathogens causing various plant diseases and possess a broad host range, including wheat, maize, soybean, sunflower, sugar beet, date palms, desert squash, oleander, almond, and so on. (Ali et al. 2020; Al-Mahmooli et al. 2013; Al-Sadi et al. 2012; Cao et al. 2018; Mirhosseini et al. 2014; Shan et al. 2017; Stack et al. 2017; Wang et al. 2021; Xia et al. 2018). Based on the DNA features, about 23 species complexes are reported in the Fusarium genus (Jacobs-Venter et al. 2018). Fusarium stalk rot of maize has been reported throughout the global maize-growing regions. Previously, we have reported Fusarium brachygibbosum Padwick strain $\mathrm{HN}-1$ as a causal agent of stalk rot disease of maize in China (Shan et al. 2017). However, the whole-genome sequence has not been reported yet. With the availability of the whole-genome sequence, understanding of the pathogen will be improved, and suitable management strategies will be developed to control disease caused by the pathogen.

Genomic DNA was purified from the mycelium of $F$. brachygibbosum Padwick strain $\mathrm{HN}-1$ using a commercial DNA extraction kit (DNASecure Plant Kit; TianGen) following the manufacturer's instructions. The integrity of harvested DNA was detected by agarose gel electrophoresis and quantified by Qubit (version 2.0). Whole-genome sequencing was performed on the Illumina HiSeq 2500-PE125 platform with massively paralleled sequencing technology by following the standard procedures (5-kb mate-pair library and 500-bp A-tailed pair-end Illumina library). The genome was sequenced by the Beijing Novogene Bioinformatics Technology Co., Ltd., Beijing, China (https://en.novogene.com). The paired reads were filtered using the compiling pipeline provided by the company. After quality control, the reads were assembled using the SOAPdenovo program (version 2.04) (Li et al. 2008, 2010). Related coding genes were retrieved using the Augustus program (version 2.7) (Stanke et al. 2008). The RepeatMasker program (version open-4.0.5) was used to predict

\footnotetext{
${ }^{\dagger}$ Corresponding author: W. Guo; guowei01@ caas.cn
}

The author(s) declare no conflict of interest.

\section{Funding}

This research work was partially supported by the National Key Research and Development Program of China (grant number 2017YFC1600903) and National Natural Science Foundation of China (grant numbers 31670143 and 32072377).

\section{Keywords}

complete-genome sequencing, Fusarium brachygibbosum, maize stalk rot disease 
Table 1. Genome assembly statistics of Fusarium brachygibbosum Padwick strain HN-1

$\begin{array}{lrr}\text { Genome assembly } & \text { Scaffold } & \text { Contig } \\ \text { Total number } & 277 & 312 \\ \text { Total length (bp) } & 40,359,238 & 40,359,238 \\ \mathrm{~N}_{50} \text { length (bp) } & 3,082,799 & 1,452,529 \\ \mathrm{~N}_{90} \text { length (bp) } & 254,325 & 156,549 \\ \text { Maximum length (bp) } & 5,093,487 & 3,330,814 \\ \text { Minimum length (bp) } & 504 & 504 \\ \text { GC content (\%) } & 47.95 & 47.95 \\ \text { Genome prediction } & & - \\ \text { Protein coding genes } & 12,510 & - \\ \text { Length of genes (bp) } & 17,349,365 & - \\ \text { Average gene length (bp) } & 1,387 & - \\ \text { Gene length per genome (\%) } & 42.99 & - \\ \text { Genome annotation } & & - \\ \text { Nonredundant databases } & 11,998 & - \\ \text { KEGG databases } & 3,870 & - \\ \text { COG } & 2,189 & - \\ \text { GO } & 7,684 & - \\ \text { TCDB } & 488 & - \\ \text { Secretory proteins } & 913 & - \\ \text { CAZymes } & 511 & 1,285 \\ \text { PHI }\end{array}$

a Abbreviations: KEGG = Kyoto Encyclopedia of Genes and Genomes, COG = clusters of orthologous groups, $\mathrm{GO}=$ gene ontology, TCDB = Transporter Classification Database, CAZymes = carbohydrate-active enzymes, and $\mathrm{PHI}=$ pathogen-host interaction.

the interspersed repetitive sequences (Saha et al. 2008), whereas tandem repeats were analyzed in Tandem Repeats Finder (version 4.07b) (Benson 1999). Transfer RNA (tRNA)and ribosomal RNA (rRNA)-related genes were predicted by tRNAscan-SE and rRNAmmer programs, respectively (Lagesen et al. 2007; Lowe and Eddy 1997). Small nuclear RNAs was predicted through a BLAST search in the Rfam database using the Cmsearch program with default parameters (Gardner et al. 2009; Nawrocki et al. 2009). A whole-genome Blastp (Altschul 1997) search (E-value < 1e-5, minimal alignment length percentage > 40\%) was performed against seven databases, including the Nonredundant Protein (NR) (Saier et al. 2016), gene ontology (GO) (Ashburner et al. 2000), Kyoto Encyclopedia of Genes and Genomes (KEGG) (Kanehisa 2006), clusters of orthologous groups (COG V9.05) (Galperin et al. 2015), Transporter Classification Database (TCDB) (Saier et al. 2016), Swiss-Prot., and TrEMBL databases (Boeckmann 2003). Secretory proteins were analyzed using Signal P (5.0) (Almagro Armenteros et al. 2019) and TMHMM (Krogh et al. 2001), whereas genes potentially involved in the pathogen-host interactions were searched in the pathogen-host interaction (PHI) database (Urban et al. 2017). For carbohydrate-active enzymes (CAZymes) prediction, related genes were searched in the CAZy database using dbCAN (Yin et al. 2012).

The assembly of the $F$. brachygibbosum genome was $40.36 \mathrm{Mb}$ (100x coverage) in size, which consists of 12,510 coding genes having GC content of $47.95 \%$. The genome comprises 277 scaffolds with a total scaffold length of $40,359,238$ bp and $N_{50}$ length of $3,082,799 \mathrm{bp}$. The maximum scaffold length was $5,093,487 \mathrm{bp}$, while the minimum scaffold length was 504 bp. In all, 11,998 genes were predicted with the average gene length of $1,387 \mathrm{bp}$ using the Augustus program. For functional annotations, 11,998, 3,870, 2,189, 7,684, and 488 genes were annotated from NR, KEGG, COG, $\mathrm{GO}$, and TCDB databases, respectively. In total, 913 putative secretory proteins were identified in the genome using Signal $P$ and TMHMM. dbCAN predicted a total of 511 genes from the CAZymes, including 250 genes related to glycoside hydrolases, 80 to glycosyl transferases, 19 related to polysaccharide lyases, 31 related to carbohydrate esterases, 71 predicted to have auxiliary activities, and 60 genes associated with carbohydrate-binding modules. Similarly, it was predicted that 1,285 genes from F. brachygibbosum $\mathrm{HN}-1$ were $\mathrm{PHI}$ genes. The genome assembly statistics are shown in Table 1. 


\section{Data Availability}

The complete genomic data have been deposited to the NCBI GenBank database under the accession number JAEKIX000000000. The genome's contig information can be assessed at NCBI under the BioProject ID PRJNA686892 and BioSample ID SAMN17127420. The version described in this article is JAEKIX000000000.1. The presented genomic information of $F$. brachygibbosum will provide a base for the researchers to design an effective control strategy against the pathogen.

\section{Acknowledgments}

We thank H. Kang at the Institute of Plant Protection, Chinese Academy of Agricultural Sciences for his consistent support for our genome projects.

\section{Literature Cited}

Ali, H., Hameed, M., Abdulrahman, A., and Saood, H. 2020. First report on Fusarium brachygibbosum isolate FIR 16_ITS isolated from Iraqi wheat plant. J. Ecol. Eng. 21:81-86.

Almagro Armenteros, J. J., Tsirigos, K. D., Sønderby, C. K., Petersen, T. N., Winther, O., Brunak, S., von Heijne, G., and Nielsen, H. 2019. SignalP 5.0 improves signal peptide predictions using deep neural networks. Nat. Biotechnol. 37:420-423.

Al-Mahmooli, I. H., Al-Bahri, Y. S., Al-Sadi, A. M., and Deadman, M. L. 2013. First report of Euphorbia larica dieback caused by Fusarium brachygibbosum in Oman. Plant Dis. 97:687.

Al-Sadi, A. M., Al-Jabri, A. H., Al-Mazroui, S. S., and Al-Mahmooli, I. H. 2012. Characterization and pathogenicity of fungi and oomycetes associated with root diseases of date palms in Oman. Crop Prot. 37:1-6.

Altschul, S. 1997. Gapped BLAST and PSI-BLAST: A new generation of protein database search programs. Nucleic Acids Res. 25:3389-3402.

Ashburner, M., Ball, C. A., Blake, J. A., Botstein, D., Butler, H., Cherry, J. M., Davis, A. P., Dolinski, K., Dwight, S. S., Eppig, J. T., Harris, M. A., Hill, D. P., Issel-Tarver, L., Kasarskis, A., Lewis, S., Matese, J. C., Richardson, J. E., Ringwald, M., Rubin, G. M., and Sherlock, G. 2000. Gene ontology: Tool for the unification of biology. Nat. Genet. 25:25-29.

Benson, G. 1999. Tandem repeats finder: A program to analyze DNA sequences. Nucleic Acids Res. 27:573-580.

Boeckmann, B. 2003. The SWISS-PROT protein knowledgebase and its supplement TrEMBL in 2003. Nucleic Acids Res. 31:365-370.

Cao, S., Yang, N., Zhao, C., Liu, J., Han, C., and Wu, X. 2018. Diversity of Fusarium species associated with root rot of sugar beet in China. J. Gen. Plant Pathol. 84:321-329.

Galperin, M. Y., Makarova, K. S., Wolf, Y. I., and Koonin, E. V. 2015. Expanded microbial genome coverage and improved protein family annotation in the COG database. Nucleic Acids Res. 43:D261-D269.

Gardner, P. P., Daub, J., Tate, J. G., Nawrocki, E. P., Kolbe, D. L., Lindgreen, S., Wilkinson, A. C., Finn, R. D., Griffiths-Jones, S., Eddy, S. R., and Bateman, A. 2009. Rfam: Updates to the RNA families database. Nucleic Acids Res. 37: D136-D140.

Jacobs-Venter, A., Laraba, I., Geiser, D. M., Busman, M., Vaughan, M. M., Proctor, R. H., McCormick, S. P., and O'Donnell, K. 2018. Molecular systematics of two sister clades, the Fusarium concolor and $F$. babinda species complexes, and the discovery of a novel microcycle macroconidium-producing species from South Africa. Mycologia 110:1189-1204.

Kanehisa, M. 2006. From genomics to chemical genomics: New developments in KEGG. Nucleic Acids Res. 34:D354-D357.

Krogh, A., Larsson, B., von Heijne, G., and Sonnhammer, E. L. L. 2001. Predicting transmembrane protein topology with a hidden Markov model: Application to complete genomes. J. Mol. Biol. 305:567-580.
Lagesen, K., Hallin, P., Rødland, E. A., Stærfeldt, H.-H., Rognes, T., and Ussery, D. W. 2007. RNAmmer: Consistent and rapid annotation of ribosomal RNA genes. Nucleic Acids Res. 35:3100-3108.

Li, R., Li, Y., Kristiansen, K., and Wang, J. 2008. SOAP: Short oligonucleotide alignment program. Bioinformatics 24:713-714.

Li, R., Zhu, H., Ruan, J., Qian, W., Fang, X., Shi, Z., Li, Y., Li, S., Shan, G., Kristiansen, K., Li, S., Yang, H., Wang, J., and Wang, J. 2010. De novo assembly of human genomes with massively parallel short read sequencing. Genome Res. 20:265-272.

Lowe, T. M., and Eddy, S. R. 1997. tRNAscan-SE: A program for improved detection of transfer RNA genes in genomic sequence. Nucleic Acids Res. 25:955-964.

Mirhosseini, H. A., Babaeizad, V., and Hashemi, L. 2014. First report of Fusarium brachygibbosum causing leaf spot on oleander in Iran. J. Plant Pathol. 96: 431.

Nawrocki, E. P., Kolbe, D. L., and Eddy, S. R. 2009. Infernal 1.0: Inference of RNA alignments. Bioinformatics 25:1335-1337.

Saha, S., Bridges, S., Magbanua, Z. V., and Peterson, D. G. 2008. Empirical comparison of ab initio repeat finding programs. Nucleic Acids Res. 36:2284-2294.

Saier, M. H., Reddy, V. S., Tsu, B. V., Ahmed, M. S., Li, C., and Moreno-Hagelsieb, G. 2016. The Transporter Classification Database (TCDB): Recent advances. Nucleic Acids Res. 44:D372-D379.

Shan, L. Y., Cui, W. Y., Zhang, D. D., Zhang, J., Ma, N. N., Bao, Y. M., Dai, X. F., and Guo, W. 2017. First report of Fusarium brachygibbosum causing maize stalk rot in China. Plant Dis. 101:837.

Stack, A. J., Yaghmour, M. A., Kirkpatrick, S. C., Gordon, T. R., and Bostock, R. M. 2017. First report of Fusarium brachygibbosum causing cankers in cold-stored, bare-root propagated almond trees in California. Plant Dis. 101: 390.

Stanke, M., Diekhans, M., Baertsch, R., and Haussler, D. 2008. Using native and syntenically mapped CDNA alignments to improve de novo gene finding. Bioinformatics 24:637-644.

Urban, M., Cuzick, A., Rutherford, K., Irvine, A., Pedro, H., Pant, R., Sadanadan, V., Khamari, L., Billal, S., Mohanty, S., and Hammond-Kosack, K. E. 2017. PHI-base: A new interface and further additions for the multi-species pathogen-host interactions database. Nucleic Acids Res. 45:D604-D610.

Wang, S., Li, X., Liu, C., Liu, L., Yang, F., Guo, Y., and Li, Y. 2021. First report of Fusarium brachygibbosum causing root rot on soybean in northeastern China. Plant Dis. 105:1560.

Xia, B., Hu, J. Y., Zhu, X. F., Liang, Y., Ren, X., Wu, Y. H., and Chen, D. X. 2018 First report of sunflower broomrape wilt caused by Fusarium brachygibbosum in China. Plant Dis. 102:2372.

Yin, Y., Mao, X., Yang, J., Chen, X., Mao, F., and Xu, Y. 2012. dbCAN: A web resource for automated carbohydrate-active enzyme annotation. Nucleic Acids Res. 40:W445-W451. 